\title{
Photocatalytic and Smart Asphalt Mixtures: a brief overview
}

\author{
I. Rocha Segundo ${ }^{* a}$, E. Freitas ${ }^{\mathrm{a}}$, S. Landi Jr. ${ }^{\text {b,c }}$, M. F. Costa ${ }^{\mathrm{d}}$, J. O. Carneiro ${ }^{\mathrm{b}}$ \\ ${ }^{a}$ Civil Engineering Department, University of Minho, Azurém Campus, Guimarães, Portugal; \\ ${ }^{\mathrm{b} C e n t r e} \&$ Department of Physics, University of Minho, Azurém Campus, Guimarães, Portugal; \\ ${ }^{\mathrm{c}}$ Federal Institute Goiano, Rio Verde - GO, Brazil; \\ ${ }^{\mathrm{d}}$ Centre \& Department of Physics, University of Minho, Gualtar Campus, Braga, Portugal
}

\begin{abstract}
Nowadays, there is an increasing concern about the use of less harmful techniques to the environment, and about road safety in Transportation Engineering. Heterogeneous photocatalysis based on the application of semiconductors materials onto asphalt mixtures is a promising technology because it can mitigate air pollution and road accidents. The functionalized asphalt mixtures with photocatalytic capability can degrade pollutants, such as damaging gases and oil/greases over their surface from specific reactions triggered by sunlight photons, providing significant environmental and social benefits. In this communication, a brief review of photocatalysis applied in asphalt mixtures will be presented.
\end{abstract}

Keywords: asphalt mixtures, photocatalysis, optical analysis, smart materials, multifunctional materials

\section{INTRODUCTION}

Road pavements must be able to withstand the effects promoted by vehicle traffic and also by the climate actions, ensuring driving conditions to meet requisites related to safety, comfort, economy and with low environmental impact on the surrounding ecosystems. Most of the recent researches about road pavements aim to improve the mechanical behavior of asphalt mixtures, but recently the functionalization and multifunctional capabilities have become a very important subject, as the asphalt pavements have a large area and can contribute to other aspects that will be discussed in this paper.

As described by Han ${ }^{1}$, a smart and multifunctional cement/asphalt/polymer concrete is a material with properties that differ from the conventional ones, which can react to external stimulus complying with those requirements, such as stress and temperature. These properties can be self-healing, self-sensing, electrically conductive, electromagnetic and thermal. A smart and multifunctional material is achieved through composition design, special processing, introduction of new functional components, or modification of the microstructure of the conventional ones ${ }^{1}$.

The smart and multifunctional concretes, by their smartness or function, are classified by smartness, mechanical function, electrical function, optical function, electromagnetic wave/radiation shielding/absorbing function, function related to water and energy-harvesting function. The optical functions are light-transmitting, light-emitting and photocatalytic ability ${ }^{1,2}$.

Heterogeneous photocatalysis mediated by semiconductors has recently attracted much interest due to its efficient ability to convert solar energy to chemical energy mainly in applications in the field of environmental remediation. In particular, several studies have achieved good results for the degradation of pollutants emitted by fossil fuel vehicles. Due to the huge surface area covered and its vicinity to the exhaust gases from automobile, the photocatalytic road pavements are quoted as promising surfaces for the reduction (in the presence of sunlight and moisture $/ \mathrm{O}_{2}$ ) of $\mathrm{NO}_{\mathrm{x}}, \mathrm{CO}_{\mathrm{x}}$, $\mathrm{HC}$ and other pollutant gases present in the atmosphere ${ }^{3-7}$. For this reason, by the fact that the photocatalytic materials can degrade organic pollutants (like oils and greases), these materials could also be classified as self-cleaning materials. In this sense, the selfcleaning property can contribute to the reduction of accidents in oil-spilled areas.

\section{BASIC PRINCIPLES OF PHOTOCATALYSIS}

The initial step of semiconductor photocatalysis occurs when a photon with an equal (or greater) energy than the band gap energy is absorbed by the semiconductor material. In this case, succeeds the production of an electron $\left(\mathrm{e}^{-}\right)$in the conduction band (CB) and a hole $\left(\mathrm{h}^{+}\right)$in the valence band (VB) of the semiconductor. The $\mathrm{e}^{-} / \mathrm{h}^{+}$photogenerated pairs can recombine in the bulk or at the surface releasing the absorbed energy as light or, more frequently, as heat. However, the charge carries can also be trapped at particular sites of the semiconductors before being transferred to the adsorbed species on their 
surface. For example, valence band holes can oxidize species like $\mathrm{OH}^{-}$and conduction band electrons can reduce species such as $\mathrm{O}_{2}$ or $\mathrm{H}^{+}$, where all these species are often present in aquatic environments or in the atmosphere (moisture). Free radicals formed from these redox reactions that start at the semiconductor surface can cause the degradation of different pollutants (organic compounds, nitric oxides, among other) ${ }^{8}$.

Specifically, for the titanium dioxide, the semiconductor most widely utilized in the field of photocatalysis, their VB is mainly constituted by the oxygen $2 p$ orbitals, whereas the $\mathrm{CB}$ is mainly formed by the $3 \mathrm{~d}$ orbitals of the $\mathrm{Ti}^{4+}$ cations ${ }^{10}$. In fact, more effective separation of the $\mathrm{e}^{-} / \mathrm{h}^{+}$pairs is achieved from the Ti defect states and surface Ti-O-Ti sites (or terminal $\mathrm{Ti}-\mathrm{OH})$, which can trap the $\mathrm{e}^{-}$and $\mathrm{h}^{+}$, respectively. In general, oxygen vacancies ${ }^{11}$, surface $\mathrm{Ti}^{3+}{ }^{12}$, Ti interstitial or even ions in the lattice or in the near surface of $\mathrm{TiO}_{2}{ }^{13}$ are responsible by formation of intra-bandgap energy levels, which are of great importance to retard the rate of $\mathrm{e}^{-} / \mathrm{h}^{+}$recombination process and at the same time it can enable the absorption of light by $\mathrm{TiO}_{2}$ not only in the ultraviolet but also in the visible region of the electromagnetic spectrum ${ }^{14-16}$.

The understanding of the charge carriers' kinetics and the associated energies of the VB and CB can be obtained from different characterization techniques. For example, diffuse reflectance spectroscopy studies analyzed in light of the Kubelka-Munk theory are commonly utilized to determine the bandgap of semiconductors. Time-resolved spectroscopy and electron spin resonance are applied to monitor the $\mathrm{e}^{-} / \mathrm{h}^{+}$pairs dynamics and to identify the radicals formed upon the transfer of the charge carriers ${ }^{17}$. Therefore, these results are essential for understanding the mechanisms underlying photocatalysis.

\section{PHOTOCATALYTIC ASPHALT PAVEMENTS}

Road pavements are ideal places for reducing air pollution because of its high paved areas as well as the close proximity between its surface and the gases emitted by the vehicles ${ }^{18}$. Fig. 1 schematizes the operational mechanism of the asphalt mixtures with photocatalytic ability, one of the most evaluated characteristics in multifunctional asphalt mixtures.

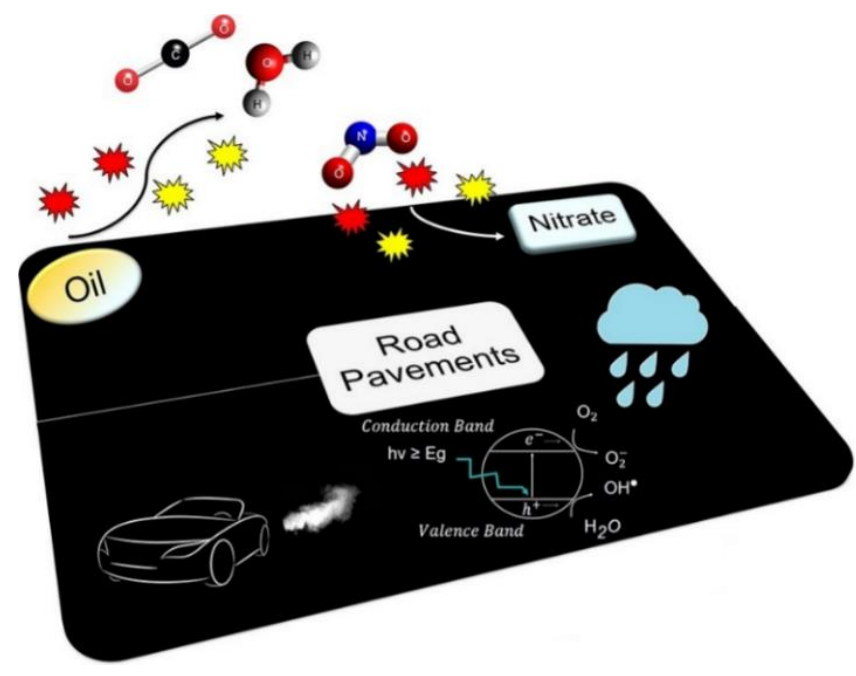

Figure 1: Photocatalytic asphalt mixture ${ }^{5}$.

In the literature about the photocatalytic capability applied on asphalt materials, it is possible to find quite a few works about conventional asphalt mixtures ${ }^{3,18}$, asphalt mixtures with lower production temperature (Warm Mix Asphalt) ${ }^{19}$, asphalt emulsions ${ }^{20}$, among others. In addition, other topics have been studied, such as their application in real context or just small test sections ${ }^{20-24}$, and the computational modeling of the photocatalytic capability of road pavements ${ }^{21}$.

In order to obtain photocatalytic asphalt mixtures, it is possible to highlight four main techniques that can be utilized to apply the semiconductor materials in the asphalt mixtures: i) spraying coating $3,6,19,25-27$, ii) volume incorporation ${ }^{3,27}$, iii) bitumen modification ${ }^{19}$, and iv) spreading ${ }^{27,28}$. Bitumen modification is developed before the fabrication of the asphalt mixture. The semiconductor particles are mixed just with the binder. The technique by volume incorporation is carried out 
during the asphalt mixture production where the particles are inserted combined with the aggregates. The spraying coating and the spreading process are applied over the asphalt mixture after its compaction. The first one, that is, the spraying coating, is carried out using a spray-painting gun and the second one (spreading process) is carried out by using a specific solution that is deposited over the surface like chip sealing or even using paintbrushes. There are other techniques to functionalize the asphalt mixtures, but probably entailing a greater degree of application difficulty and also leading to a higher cost of implementation in a real context, such as the use of the atmospheric plasma spraying technique ${ }^{24}$.

The first technique, i.e., the spraying coating, is the most efficient and uses less amount of semiconductor materials, but the immobilization of the semiconductor particles over the surface is a major challenge. The second and third functionalization processes, i.e., the volume incorporation and bitumen modification respectively, probably guarantee the best immobilization characteristics but uses more material compared with the other ones. Nevertheless, traffic abrasion is necessary to expose the semiconductor materials covered by bitumen.

The modification technique improves the aging resistance of asphalt binders mainly due to the capability of the semiconductors reflect and absorb the UV light, which is the most important issue for the long-term aging process ${ }^{19,29-31}$. Additionally, $\mathrm{TiO}_{2}$ nanoparticles as bitumen modifier decrease the acid component and increase the alkaline component and also the surface free energy of the asphalt binder, leading in improvements in the adhesion between the asphalt binder and the aggregate ${ }^{32}$.

Regarding the spraying coating technique, the literature reports the application of aqueous solutions ${ }^{3,6,19,25}$ and other ones with emulsions ${ }^{20}$, cement and resins ${ }^{28,33}$, polymers ${ }^{34}$ and rubber ${ }^{22}$ in order to achieve a better immobilization process. An important concern that should be taken into account when it is desired to obtain photocatalytic aqueous solutions is the dispersion of the $\mathrm{TiO}_{2}$ nanoparticles; otherwise they may agglomerate and, consequently, decrease the photocatalytic efficiency. Some authors submitted $\mathrm{TiO}_{2}$ solutions to ultrasonic treatment ${ }^{26,27}$ or prepared aqueous solutions with a value of zeta potential different from the isoelectric point ${ }^{3}$. The previews preparation reduces the agglomeration of particles because of the van der Waals attraction forces that should be competing with the repulsive electrostatic forces ${ }^{3}$. For the preparation of the $\mathrm{TiO}_{2}$ aqueous solution, the recommendation is to use a $\mathrm{pH} 8^{3}$.

The semiconductor $\mathrm{TiO}_{2}$ activates the photocatalysis when it is irradiated with UV light from sunlight. Nevertheless, the sunlight is composed mostly of visible and infrared lights, having a very short UV light irradiance, only 3-5\% of the solar spectrum corresponds to the UV range ${ }^{35}$. In this sense, one of the most important concerns reported in literature review to obtain improved photocatalytic materials is the doping of $\mathrm{TiO}_{2}$ particles with different materials in order to decrease its band gap to the wavelength range of visible light, thus promoting the degradation of pollutants when subjected to the incidence of photons in the visible range ${ }^{26,35}$. So, in asphalt mixtures, the functionalization by La-doped ${ }^{26}, \mathrm{Ce}^{2} \mathrm{doped} \mathrm{TiO}_{2}$ ${ }^{27}$, both by ultrasonic assisted sol-gel and by $\mathrm{N}$-doped ${ }^{36} \mathrm{TiO}_{2}$ by a simple mixing have been studied by several authors. The authors concluded that $\mathrm{TiO}_{2}$ doped with $0.5 \%$ of $\mathrm{La}^{26}$ and $0.2 \%$ of $\mathrm{Ce}^{27}$ presented the optimal photocatalytic efficiency. All these treatments could degrade NO under both ultraviolet and visible light.

In order to measure this capability, the literature presents tests of $\mathrm{NO}_{\mathrm{x}}$ degradation efficiency according to the standards ISO 22197-1 and JIS TR Z $0018^{19,27,37}$, and tests of photocatalytic efficiency by degradation of different organic dyes, such as methylene blue (MB) and Rhodamine B (RhB), using spectrophotometry ${ }^{3,4,27}$ (Fig. 2). Considering the first test, a gas flow (usually $\mathrm{NO}, \mathrm{NO}_{2}$ or $\mathrm{NO}_{\mathrm{x}}$ ) with a controlled concentration passes through a chamber where the sample is placed and also irradiated (Fig. 2a). The concentration of the gas is monitored at the outlet of the system. By using this procedure, the photocatalytic efficiency can be further evaluated. It is possible to control humidity, temperature, the light irradiation (wavelengths and intensity), flow rate, concentration, and other physical parameters. The second one, the organic dye degradation, the samples under study are immersed in a solution of dye (usually Methylene blue - MB - or Rhodamine B - RhB) with a known initial concentration and monitoring over time the variation of the solution concentration exposed to light irradiation (Fig. 2b and c). For this case, by applying the Beer-lambert law, the photocatalytic efficiency can be calculated from detected variations (decrease) in the maximum absorbance of the absorption spectrum acquired by optical spectroscopy. 

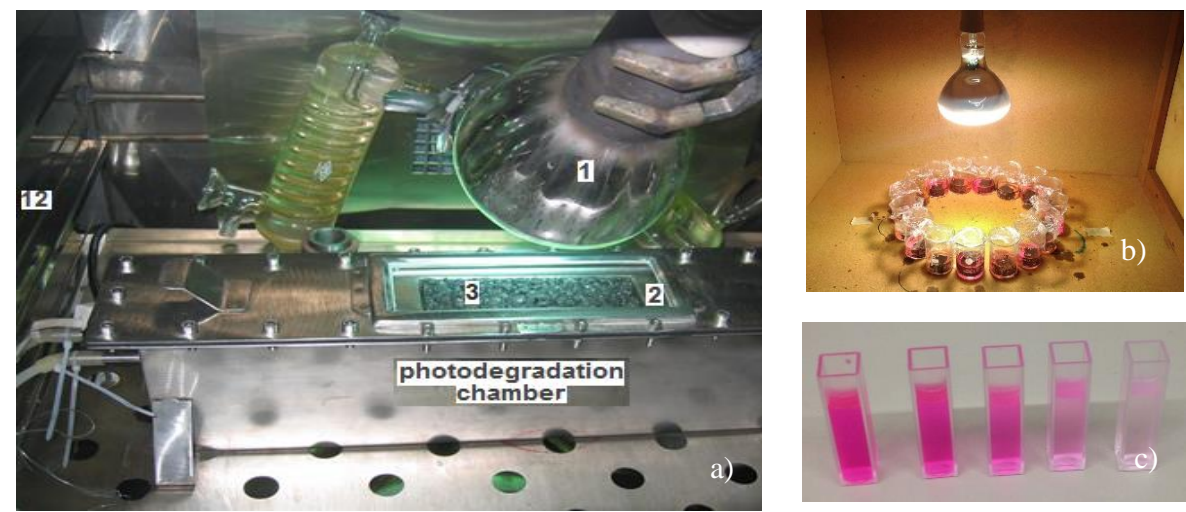

Figure 2: Tests for measuring the photocatalytic activity: a) NOx degradation efficiency; b) organic dye degradation; c) different color intensity indicating the degradation.

The photocatalytic efficiency can be influenced by several factors, such as pollutant flow rate and concentration, solar irradiation, humidity, environmental temperature, etc. Due to the action of traffic and wind speed, a reduction in NOx efficiency usually occurs in about $60 \%$ and $42 \%$, respectively ${ }^{23}$. An increase of the solar irradiation also leads to the concomitant increase in the photocatalytic efficiency. The presence of excessive water inhibits the photocatalytic reaction as humidity competes with pollutants for adsorption over the surface, thus decreasing the photocatalytic efficiency ${ }^{6,23,24}$ On the other hand, the increase of gas flow rate decreases the photocatalytic efficiency due to insufficient photocatalytic reaction under high gas flow velocity, because it diminishes the contact time between the reactants and the catalyst ${ }^{6,26}$. Moreover, the concentration of the gas also influences the photocatalytic efficiency. The higher the concentration, the lower the photocatalytic efficiency ${ }^{22,26}$. Shorter radiation wavelengths are more effective than longer wavelengths ${ }^{22,24}$. It has also been observed a decrease in photocatalytic efficiency when the samples are submitted to higher temperatures, which can be explained by the higher kinetic energy of the molecules, thus accelerating their gasification and reducing the contact of the gas with the semiconductor material ${ }^{22}$.

Photocatalytic surfaces are also considered self-cleaning due to the ability to degrade organic pollutants, such as adsorbed oils and greases. Under a road safety context, this degradation can avoid problems of skidding caused when the pavements are contaminated by those organic compounds, thus contributing positively to the reduction of car accidents ${ }^{3}$.

\section{CONCLUSIONS}

The photocatalytic asphalt mixtures behave like smart materials since they present new capabilities when subjected to the action of light (optical interaction). These new capabilities are provided by the presence of semiconductors materials, such as $\mathrm{TiO}_{2}$ usually utilized at the nanometer scale and applied by using four main methods: spraying coating, bitumen modification, volume incorporation and spreading.

The semiconductor $\mathrm{TiO}_{2}$ activates the photocatalysis when it is irradiated with UV light from sunlight. Nevertheless, the sunlight is composed of only 3-5\% of UV range light. Thus, many research efforts have been performed in order to decrease the energy band gap to the visible range of the electromagnetic spectrum; a strategy consists on the implementation of a $\mathrm{TiO}_{2}$-doping process with different chemical elements, aiming to obtain an improvement in the photocatalytic efficiency. Under the scope of road pavements, the photocatalytic efficiency can be evaluated by $\mathrm{NO}_{\mathrm{x}}$ degradation, and monitoring over time the variation of the concentration of a particular organic dye.

Some variables can influence the photocatalytic efficiency, such as pollutant flow rate and concentration, solar irradiation, humidity, and environmental temperature. In general, a high concentration of pollutants, high environmental temperature, high relative humidity, high gas flow rate, high traffic, and wind speed contribute to decreasing the photocatalytic efficiency. On the other hand, a high level of solar irradiation increases photocatalytic efficiency. In addition, the incidence of photons with higher energy becomes more effective than photons with longer wavelengths.

It can be concluded that photocatalytic road pavements are very important since they can be used in places where there are high emissions of pollutants (typically in areas with a high density of urban mesh), since these modified road structures are characterized by having a big surface area and therefore have great potential to effectively promote photocatalytic 
reactions with the surrounding pollutants and thus, contributing to improving the health conditions of the populations that live in those great urban centers. However, in real context scenarios (functionalized pavements with great extension - tens or hundreds of kilometers) the application experience is unsatisfactory, and problems associated with the surface immobilization of the semiconductor materials needs further studies.

\section{ACKNOWLEDGMENTS}

This work was partially financed by FCT - Fundação para a Ciência e a Tecnologia - under the project PTDC/FIS/120412/2010: "Nanobased concepts for Innovative \& Eco-sustainable constructive material's surfaces" and project PEst-OE/ECI/UI4047/2019. Also, the first author would like to acknowledge FCT for the PhD scholarship (SFRH/BD/137421/2018).

\section{REFERENCES}

[1] Han, B., Zhang, L. and Ou, J., [Smart and Multifunctional Concrete Toward Sustainable Infrastructures], Springer, Heidelberg (2017).

[2] Han, B., Wang, Y., Dong, S., Zhang, L. and Ding, S., "Smart concretes and structures: A review" (2015).

[3] Carneiro, J. O. O., Azevedo, S., Teixeira, V., Fernandes, F., Freitas, E., Silva, H. and Oliveira, J., "Development of photocatalytic asphalt mixtures by the deposition and volumetric incorporation of $\mathrm{TiO}_{2}$ nanoparticles," Constr. Build. Mater. 38, 594-601 (2013).

[4] Rocha Segundo, I., Ferreira, C., Freitas, E. F., Carneiro, J. O., Fernandes, F., Landi Júnior, S. and Costa, M. F., "Assessment of photocatalytic, superhydrophobic and self-cleaning properties on hot mix asphalts coated with $\mathrm{TiO}_{2}$ and/or $\mathrm{ZnO}$ aqueous solutions," Constr. Build. Mater. 166, 36-44 (2018).

[5] Rocha Segundo, I., Landi Jr., S., Oliveira, S. M. B., Freitas, E. F. de and Carneiro, J. A. O., "Photocatalytic Asphalt Mixtures: Mechanical Performance and Impacts of Traffic and Weathering Abrasion on Photocatalytic Efficiency," Catal. Today(July) (2018).

[6] Hassan, M., Mohammad, L. N., Asadi, S., Dylla, H. and Cooper, S., "Sustainable Photocatalytic Asphalt Pavements for Mitigation of Nitrogen Oxide and Sulfur Dioxide Vehicle Emissions," J. Mater. Civ. Eng. 25(March) (2012).

[7] Fujishima, A., Rao, T. N. and Tryk, D. A., "Titanium dioxide photocatalysis," J. Photochem. Photobiol. C Photochem. Rev. 1(1), 1-21 (2000).

[8] Landi, S., Carneiro, J., Ferdov, S., Fonseca, A. M., Neves, I. C., Ferreira, M., Parpot, P., Soares, O. S. G. P. and Pereira, M. F. R., "Photocatalytic degradation of Rhodamine B dye by cotton textile coated with $\mathrm{SiO}_{2}-\mathrm{TiO}_{2}$ and $\mathrm{SiO}_{2}-\mathrm{TiO}_{2}-\mathrm{HY}$ composites," J. Photochem. Photobiol. A Chem. 346, 60-69 (2017).

[9] Zhao, J. and Yang, X., "Photocatalytic oxidation for indoor air purification: A literature review," Build. Environ. 38(5), 645-654 (2003).

[10] Hernández-Alonso, M., Fresno, F., Suárez, S. and Coronado, J., "Development of alternative photocatalysts to $\mathrm{TiO}_{2}$ : Challenges and opportunities," Energy Environ. Sci. 2, 1231-1257 (2009).

[11] Schneider, J., Matsuoka, M., Takeuchi, M., Zhang, J., Horiuchi, Y., Anpo, M. and Bahnemann, D. W., "Understanding $\mathrm{TiO}_{2}$ Photocatalysis: Mechanisms and Materials," Chem. Rev. 114(19), 9919-9986 (2014).

[12] Riyapan, S., Boonyongmaneerat, Y., Mekasuwandumrong, O., Praserthdam, P. and Panpranot, J., "Effect of surface $\mathrm{Ti}^{3+}$ on the sol-gel derived $\mathrm{TiO}_{2}$ in the selective acetylene hydrogenation on $\mathrm{Pd} / \mathrm{TiO}_{2}$ catalysts," Catal. Today 245, 134-138 (2015).

[13] "Reactivity of Trapped and Accumulated Electrons in Titanium Dioxide Photocatalysis.”, Catalysts 7(10) (2017).

[14] Mohammadyari, P. and Nezamzadeh-ejhieh, A., "RSC Advances Supporting of mixed ZnS - NiS semiconductors onto clinoptilolite nano-particles to improve its activity in photodegradation of 2-nitrotoluene," RSC Adv. 5, 75300-75310 (2015).

[15] Esmaili-Hafshejani, J. and Nezamzadeh-Ejhieh, A., "Increased photocatalytic activity of $\mathrm{Zn}(\mathrm{II}) / \mathrm{Cu}(\mathrm{II})$ oxides and sulfides by coupling and supporting them onto clinoptilolite nanoparticles in the degradation of benzophenone aqueous solution," J. Hazard. Mater. 316, 194-203 (2016).

[16] Nezamzadeh-Ejhieh, A. and Bahrami, M., "Investigation of the photocatalytic activity of supported $\mathrm{ZnO}_{-} \mathrm{TiO}_{2}$ on clinoptilolite nano-particles towards photodegradation of wastewater-contained phenol," Desalin. Water Treat. 
55(4), 1096-1104 (2015).

[17] Zong, H., Schneider, J., Zhou, G., Zhao, T., Li, Y., Yang, J., Detlef, W. and Pan, J. H., “Charge Carrier Trapping, Recombination and Transfer during $\mathrm{TiO}_{2}$ Photocatalysis: An Overview," Catal. Today (2018).

[18] Toro, C., Jobson, B. T., Haselbach, L., Shen, S. and Chung, S. H., "Photoactive roadways: Determination of CO, $\mathrm{NO}$ and VOC uptake coefficients and photolabile side product yields on $\mathrm{TiO}_{2}$ treated asphalt and concrete," Atmos. Environ. 139, 37-45 (2016).

[19] Hassan, M. M., Dylla, H., Asadi, S., Mohammad, L. N. and Cooper, S., "Laboratory Evaluation of Environmental Performance of Photocatalytic Titanium Dioxide Warm-Mix Asphalt Pavements," J. Mater. Civ. Eng. 24(5), 599_ 605 (2012).

[20] Bocci, E., Riderelli, L., Fava, G. and Bocci, M., "Durability of NO Oxidation Effectiveness of Pavement Surfaces Treated with Photocatalytic Titanium Dioxide,” Arab. J. Sci. Eng., 1-7 (2016).

[21] Dylla, H., Asadi, S., Hassan, M. and Mohammad, L. N., "Evaluating photocatalytic asphalt pavement effectiveness in real-world environments through developing models: a statistical and kinetic study," Road Mater. Pavement Des. 14(sup2), 92-105 (2013).

[22] Liu, W., Wang, S., Zhang, J. and Fan, J., "Photocatalytic degradation of vehicle exhausts on asphalt pavement by $\mathrm{TiO}_{2} /$ rubber composite structure," Constr. Build. Mater. 81(x), 224-232 (2015).

[23] Asadi, S., Hassan, M., Nadiri, A. and Dylla, H., "Artificial intelligence modeling to evaluate field performance of photocatalytic asphalt pavement for ambient air purification,” Environ. Sci. Pollut. Res. 21(14), 8847-8857 (2014).

[24] Chen, M. and Liu, Y., "NOx removal from vehicle emissions by functionality surface of asphalt road," J. Hazard. Mater. 174(1-3), 375-379 (2010).

[25] Venturini, L. and Bacchi, I., "Research , Design and Development of a Photocatalytic Asphalt Pavement," 1-16 (2009).

[26] Tang, B., Liu, X., Huang, W. and Cao, X., "Preparation of La-doped nanometer $\mathrm{TiO}_{2}$ and its application for NO removal on asphalt concrete," Road Mater. Pavement Des. 18(S3), 43-53 (2017).

[27] Cao, X., Yang, X., Li, H., Huang, W. and Liu, X., "Investigation of Ce- $\mathrm{TiO}_{2}$ photocatalyst and its application in asphalt- based specimens for NO degradation," Constr. Build. Mater. 148, 824-832 (2017).

[28] Wang, D., Leng, Z., Yu, H., Hüben, M., Kollmann, J. and Oeser, M., "Durability of epoxy-bonded TiO 2 -modified aggregate as a photocatalytic coating layer for asphalt pavement under vehicle tire polishing," Wear 382(March), 1-7 (2017).

[29] Rocha Segundo, I. G. da, Dias, E. A. L., Fernandes, F. D. P., Freitas, E. F. de, Costa, M. F. and Carneiro, J. O., "Photocatalytic asphalt pavement: the physicochemical and rheological impact of $\mathrm{TiO}_{2}$ nano/microparticles and ZnO microparticles onto the bitumen," Road Mater. Pavement Des. (2018).

[30] Nazari, H., Naderi, K. and Moghadas Nejad, F., "Improving aging resistance and fatigue performance of asphalt binders using inorganic nanoparticles," Constr. Build. Mater. 170(May), 591-602 (2018).

[31] Sun, S. S., Wang, Y. M. and Zhang, A. Q., "Study on Anti-Ultraviolet Radiation Aging Property of TiO $\mathrm{Modified}^{2}$ Asphalt," Adv. Mater. Res. 306-307, 951-955 (2011).

[32] Azarhoosh, A., Moghaddas Nejad, F. and Khodaii, A., "Evaluation of the effect of nano- $\mathrm{TiO}_{2}$ on the adhesion between aggregate and asphalt binder in hot mix asphalt," Eur. J. Environ. Civ. Eng., 1-16 (2016).

[33] Wang, D., Leng, Z., Hüben, M., Oeser, M., Steinauer, B., Huben, M., Oeser, M. and Steinauer, B., "Photocatalytic pavements with epoxy-bonded $\mathrm{TiO}_{2}$-containing spreading material," Constr. Build. Mater. 107, 44-51 (2016).

[34] Leng, Z. and Yu, H., "Novel method of coating titanium dioxide on to asphalt mixture based on the breath figure process for air-purifying purpose,” J. Mater. Civ. Eng. 28(5), 1-7 (2016).

[35] Carneiro, J. O., Azevedo, S., Fernandes, F., Freitas, E., Pereira, M., Tavares, C. J., Lanceros-Méndez, S. and Teixeira, V., "Synthesis of iron-doped $\mathrm{TiO}_{2}$ nanoparticles by ball-milling process: the influence of process parameters on the structural, optical, magnetic, and photocatalytic properties," J. Mater. Sci. 49(21), 7476-7488 (2014).

[36] Chen, M., Baglee, D., Chu, J. W., Du, D. and Guo, X., "Photocatalytic Oxidation of NOx under Visible Light on Asphalt-Pavement Surface,” J. Mater. Civ. Eng. 29(9), 04017133 (2017).

[37] Osborn, D., Hassan, M., Asadi, S. and White John, R., "Durability Quantification of $\mathrm{TiO}_{2} \mathrm{Surface}_{\mathrm{Coating}}$ on Concrete and Asphalt Pavements," J. Mater. Civ. Eng. 26, 331-337 (2014). 